\title{
Reactions of Soybean Germplasm Accessions to Six Phakopsora pachyrhizi Isolates from the United States
}

\author{
Chandra Paul, ${ }^{1}$ Hélder Z. Motter, ${ }^{2}$ and David R. Walker ${ }^{3, \dagger}$ \\ ${ }^{1}$ Department of Crop Sciences, University of Illinois at Urbana-Champaign, Urbana, IL 61801, U.S.A. \\ ${ }^{2}$ Department of Plant Pathology, Federal University of Viçosa, Viçosa, MG, Brazil \\ ${ }^{3}$ United States Department of Agriculture-Agricultural Research Service Soybean/Maize Germplasm, Pathology and Genetics \\ Research Unit, and Department of Crop Sciences, University of Illinois at Urbana-Champaign
}

\begin{abstract}
Soybean rust, caused by Phakopsora pachyrhizi Syd. \& P. Syd., is one of the most economically important foliar diseases of soybean. Resistant cultivars could reduce yield losses and management costs but considerable pathogenic diversity exists among populations of the fungus; thus, resistance to a range of pathotypes is essential. Seedling and detachedleaf assays were conducted to characterize the resistance of 55 soybean plant introductions (PIs) to six purified isolates of $P$. pachyrhizi originating from the southern United States. In the greenhouse resistance assays, the differentials Hyuuga (PI 506764) and PI 471904 and accessions PI 224268, PI 567025A, PI 567039, PI 567046A, and DT 2000 (PI 635999 ) were resistant to all six isolates, including Florida isolates from

developed reddish-brown reactions to all six isolates, with an average of only 0.23 to 0.55 uredinia/lesion. These included Hyuuga, DT 2000 , two differentials with a resistance allele at the Rpp 5 locus, and accessions PI 224268, PI 423960B, PI 567025A, and PI 567046A. Many of the resistant accessions have subsequently been reported to have a resistance allele at the Rpp3 locus, and two others have resistance genes at the Rpp4 or Rpp6 locus. This study provided new information about resistance reaction phenotypes that can be useful for understanding mechanisms of resistance, which Rpp genes and alleles could be combined to obtain broader and more durable rust resistance in soybean cultivars, and pathotype diversity among the six isolates used.
\end{abstract} 2011 and 2012 that were able to defeat resistance conditioned by the Rpp1 through Rpp4 genes. Twenty-six other PIs were resistant to four or five of the six isolates. In the detached-leaf assays, eight accessions
Keywords: cultivar/resistance < disease, Phakopsora pachyrhizi, soybean, soybean rust
Soybean rust (SBR), caused by Phakopsora pachyrhizi Syd. \& P. Syd., is one of the most economically important foliar diseases of soybean (Glycine $\max$ (L.) Merr.) worldwide. It is most often a threat to soybean in production regions with mild winter temperatures. The

${ }^{\dagger}$ Corresponding author: D. R. Walker, E-mail: david.walker@usda.gov

Mention of trade names or commercial products in this publication is solely for the purpose of providing specific information and does not imply recommendation or endorsement by the U.S. Department of Agriculture. The U.S. Department of Agriculture (USDA) prohibits discrimination in all its programs and activities on the basis of race, color, national origin, age, or disability, and where applicable, sex, marital status, familial status, parental status, religion, sexual orientation, genetic information, political beliefs, reprisal, or because all or part of an individual's income is derived from any public assistance program. (Not all prohibited bases apply to all programs.) Persons with disabilities who require alternative means for communication of program information (Braille, large print, audiotape, etc.) should contact USDA's TARGET Center at (202) 720-2600 (voice and TDD). To file a complaint of discrimination, write to USDA, Director, Office of Civil Rights, 1400 Independence Avenue, S.W., Washington, D.C. 20250-9410, or call (800) 795-3272 (voice) or (202) 720-6382 (TDD). The USDA is an equal opportunity provider and employer.

Funding: This study was funded by the United States Department of Agriculture-Agricultural Research Service and H. Z. Motter was supported by the Coordination for the Improvement of Higher Education Personnel (CAPES) program of the Brazilian Ministry of Education.

*The $\boldsymbol{e}$-Xtra logo stands for "electronic extra" and indicates that four supplementary tables are published online.

The author(s) declare no conflict of interest.

Accepted for publication 3 November 2019.

This article is in the public domain and not copyrightable. It may be freely reprinted with customary crediting of the source. The American Phytopathological Society, 2020. pathogen is endemic to East Asia but it has gradually spread from there to Africa and the Americas. In South America, it was first found in Paraguay and Brazil in 2001 (Yorinori et al. 2005), and the first positive identification in the United States was made in November 2004 (Schneider et al. 2005). Although the disease can be managed effectively with mixtures of strobilurin and triazole fungicides, this adds to production costs, and the overuse of some fungicide chemistries has resulted in resistance to demethylation inhibitors and quinone-outside-inhibitors in some $P$. pachyrhizi populations and isolates from South America (Godoy 2012; Schmitz et al. 2014).

Resistant evaluation studies have identified more than 120 SBRresistant germplasm accessions (plant introductions [PIs]) in the United States Department of Agriculture (USDA) Soybean Germplasm Collection (Miles et al. 2008; Walker et al. 2011, 2014a,b) but pathogenic variation within and among $P$. pachyrhizi is high, and none of the resistant soybean accessions has been resistant to all of the isolates it has been challenged with. Susceptible soybean plants develop a "TAN" infection type, characterized by the extrusion of clumps of urediniospores from uredinia (Bromfield 1984). The tan or beige color can be from host tissue discoloration or clumps of urediniospores that have been extruded from lesions. Highly resistant, immune hosts have a type 0 infection type with no macroscopically visible lesions; however, most resistant hosts develop reddish-brown (RB) lesions, which often have some uredinia but limited sporulation compared with susceptible hosts. The level of sporulation can vary within both the TAN and RB reaction types, however, indicating that there is variability in how well different host genotypes can recognize and react to P. pachyrhizi infections (Bromfield 1984).

Thus far, seven independent loci with SBR resistance (Rpp) genes have been reported, and several of those are known to have multiple resistance alleles based on differential reactions to fungal isolates (Childs et al. 2018a). Although most of the resistance genes are dominant, recessive and partially dominant alleles have also been reported (Garcia et al. 2008). Walker et al. (2011, 2014a) reported the resistance of more than $100 \mathrm{PIs}$ to $P$. pachyrhizi field populations at various locations in the southern United States. However, the 
pathotype composition of those field populations of the fungus was unknown. Twizeyimana et al. (2011) reported that $>90 \%$ of the total genetic diversity of 116 Nigerian isolates existed within individual fields that were in the same geographical zone. In an investigation of pathogenic variation among 72 purified isolates from the United States, Twizeyimana and Hartman (2012) identified three pathotypes based on virulence and six aggressiveness groups based on the level of sporulation from uredinia. The germplasm screening studies by Walker et al. (2011, 2014a) also demonstrated that $P$. pachyrhizi pathotype diversity between growing seasons and among locations within a growing season can vary considerably in the southern United States.

To develop soybean cultivars with broad and durable resistance to $\mathrm{SBR}$, it is critical for breeders to know which known Rpp genes provide the most effective resistance in the geographical target area, and which soybean germplasm accessions have resistance to a majority of the fungal field populations and isolates from the targeted region (Childs et al. 2018a). Screening soybean germplasm accessions in the field has been effective for identifying those with moderate to high levels of SBR resistance in most year-location environments where disease pressure is sufficiently high and uniform in a field (Walker et al. 2011, 2014a). The reactions of highly susceptible and highly resistant hosts are generally relatively simple to assess unless there is a high density of lesions caused by other pathogens such as Xanthomonas axonopodis pv. glycines, which causes bacterial pustule, or Peronospora manshurica, an oomycete that causes downy mildew. Although lesions caused by other pathogens can usually be distinguished from SBR lesions, an abundance of non-SBR lesions slows or severely interferes with the process of rating SBR severity, particularly if the host has the RB infection type. Field ratings can also be more complicated, however, on plants with only moderate levels of resistance, or if there are differential interactions between the resistance genes in a host plant and multiple pathotypes present in the local Phakopsora pachyrhizi population that result in TAN and RB infection types on the same leaf.

The objectives of this study were to confirm and more thoroughly characterize the SBR reactions of some of the soybean PIs that had previously appeared to be resistant to field populations of $P$. pachyrhizi in the southern United States or in Paraguay. The PIs were challenged with six different isolates collected between 2008 and 2012.

\section{Materials and Methods}

Greenhouse inoculation experiment. In the first experiment, 45 G. max lines were inoculated with the six U.S. P. pachyrhizi isolates shown in Table 1. The experimental design was a randomized complete block with three replications. Of primary interest were 30 accessions from the USDA Soybean Germplasm Collection, many of which had been resistant to SBR in field evaluations in the southeastern United States (Walker et al. 2011, 2014a,b) or in detached-leaf assays with U.S. isolates (Paul and Hartman 2009; Paul et al. 2011). Eleven of the entries were included as differentials with known resistance genes, including the original sources of Rppl through Rpp6 and several accessions with alternative alleles at the Rpp1 and Rpp5 loci. Hyuuga (PI 506764), which has resistance genes at the Rpp3 and Rpp5 loci (Kendrick et al. 2011), was also included. Although some resistance genes such as the Rppl-b allele in PI 594538A and the Rpp5 allele from PI 200526 were already known to be ineffective against U.S. field populations of $P$. pachyrhizi, PIs with those genes were also included. Williams 82 (PI 518671)
(Bernard and Cremeens 1988), 5601T (PI 630984) (Pantalone et al. 2003), and two maturity group IV breeding lines (LD002817P from the University of Illinois and R00-1194F from the University of Arkansas) were used as susceptible checks.

The $P$. pachyrhizi isolates had all been purified through three sequential cycles of transferring a few urediniospores from a single, isolated uredinium to a fresh detached leaf of the SBR-susceptible cultivar Williams 82. It was surmised that at least one of the uredinia was likely to have originated from infection by a single urediniospore in the previous inoculation. The isolates were originally collected in Alabama (in 2008 and 2009), Louisiana (2009), or Florida (2009, 2011, and 2012), and all of them readily reproduced on susceptible soybean leaves (Table 1). The Alabama isolates originated from soybean plants at Auburn University's Gulf Coast Substation in Fairhope, AL, and the LA09-BC isolate came from soybean plants growing in northwestern Louisiana at the Louisiana State University AgCenter's Red River Research Station in Bossier City. The three Florida isolates were from soybean plants growing at the University of Florida's North Florida Research and Education Center in Quincy, FL. The source soybean plants for the FL12-Q isolate had previously been inoculated with urediniospores collected from infected kudzu (Pueraria spp.) plants growing on the same station. The unpurified isolate was found to be highly aggressive on soybean and able to reproduce on plants with the Rppl and Rpp6 resistance genes, and the FL12-Q isolate used in this study was subsequently purified from it. The Alabama and Louisiana isolates were maintained and increased on leaves of susceptible hosts, primarily Williams 82. The 2011 and 2012 Florida isolates, which were known to be virulent on hosts with the Rppl and Rpp6 genes (Paul et al. 2013), were maintained on PI 200492, the source of the original Rppl gene. The purpose of this was to prevent loss of virulence, a phenomenon that we had previously observed in another highly virulent isolate maintained for several months on a susceptible host.

Inoculation methods were the same as those described by Paul et al. (2013). Urediniospores were suspended in a solution of $0.01 \%$ Tween 20 in autoclaved distilled water and filtered through a 53- $\mu \mathrm{m}$ sieve to remove clumped spores. The suspensions were then diluted to a concentration of $4 \times 10^{4}$ urediniospores $/ \mathrm{ml}$ prior to inoculation. The abaxial sides of the first trifoliate leaf on each plant were inoculated by spraying them until runoff using a Paasche H1208 single-action, siphon-fed airbrush (Paasche Airbrush Co., Taiwan) at a pressure of $1.4 \times 10^{5} \mathrm{~Pa}$. Inoculated plants were incubated for $24 \mathrm{~h}$ in a mist chamber to promote infection. The greenhouse room was maintained at temperatures ranging between $22^{\circ} \mathrm{C}$ during the day and $20^{\circ} \mathrm{C}$ at night, with a 14-h photoperiod.

Reactions to the six $P$. pachyrhizi isolates were evaluated 14 days postinoculation using several criteria. Infection type was noted as being either TAN (susceptible), RB (incomplete resistance), or IM (immune or type 0 ) if no symptoms or signs of disease were visible. SBR severity on the first trifoliate leaf of each plant was rated on a scale of 1 to 5 , in which 1 indicated that there were no visible symptoms or signs of infection, 2 corresponded to severity ranging from 1 to $10 \%, 3$ corresponded to approximately 11 to $25 \%, 4$ to 26 to $50 \%$, and 5 indicated that at least $50 \%$ of the abaxial surface of a sample leaflet was covered with SBR lesions. Two $1.0-\mathrm{cm}^{2}$ circles were marked on either side of the midrib of a sample leaflet, and the numbers of lesions and uredinia inside each circle were counted. Mean lesion and uredinia densities were then calculated from those data and were used to calculate the average number of uredinia per lesion. Plants with

Table 1. Purified isolates of Phakopsora pachyrhizi used in soybean rust greenhouse seedling assays and detached-leaf assays

\begin{tabular}{llll}
\hline Isolate name & \multicolumn{1}{c}{ Geographical origin } & Coordinates & Year collected \\
\hline AL08-FH & Fairhope, AL (southern Alabama) & $30^{\circ} 32^{\prime} \mathrm{N}, 87^{\circ} 52^{\prime} \mathrm{W}$ & 2008 \\
AL09-FH & Fairhope, AL (southern Alabama) & $30^{\circ} 32^{\prime} \mathrm{N}, 87^{\circ} 52^{\prime} \mathrm{W}$ & 2009 \\
LA09-BC & Bossier City, LA (northwestern Louisiana) & $32^{\circ} 25^{\prime} \mathrm{N}, 93^{\circ} 38^{\prime} \mathrm{W}$ & 2009 \\
FL09-Q & Quincy, FL (north-central Florida) & $30^{\circ} 32^{\prime} \mathrm{N}, 84^{\circ} 35^{\prime} \mathrm{W}$ & 2009 \\
FL11-Q & Quincy, FL (north-central Florida) & $30^{\circ} 32^{\prime} \mathrm{N}, 84^{\circ} 35^{\prime} \mathrm{W}$ & 2011 \\
FL12-Q & Quincy, FL (north-central Florida) & $30^{\circ} 32^{\prime} \mathrm{N}, 84^{\circ} 35^{\prime} \mathrm{W}$ & 2012 \\
\hline
\end{tabular}


either no visible reaction or with RB lesions, or with significantly fewer uredinia per lesion than the susceptible checks were considered to be resistant.

Detached-leaf inoculation experiment. Detached-leaf inoculation assays were conducted to investigate the reactions of $27 \mathrm{ac}-$ cessions from the USDA Soybean Germplasm Collection, two susceptible checks, and the Rpp1 backcross line L85-2378 to the six isolates used in the greenhouse assays (Supplementary Tables S3 and S4). A randomized complete block design with three replications was used. Nineteen PIs with unknown resistance genes were assayed, including 14 accessions that were not in the greenhouse experiment. One of these, PI 567046C, was a different subline from PI $567046 \mathrm{~A}$, which was assayed in both the greenhouse and detachedleaf experiments. The other accessions not previously tested in the greenhouse assay were PI 200487, PI 416778, PI 417126, PI 417129B, PI 423959, PI 423960B, PI 506938, PI 518295, PI 567024, PI 567054C, PI 567104B, and PI 594796. Nine accessions were included as differential genotypes representing the Rppl through Rpp6 resistance genes alone, and the combination of resistance genes at the Rpp3 and Rpp5 loci in Hyuuga (PI 506764). L85-2378 (PI 547875) is an isoline of Williams 82 into which the Rppl gene from PI 200492 was backcrossed by R. L. Bernard. Data from some other studies suggest that PI 200487 and PI 471904 might have different alleles of the Rpp5 gene (Garcia et al. 2008). PI 605823 could also be regarded as a differential because it is now known to have the Rpp7 gene (Childs et al. 2018b). The lines used as susceptible controls were Williams 82 and LD00-3309 (PI 739740), a maturity group IV breeding line from the University of Illinois (Diers et al. 2006).

Seedlings from each soybean accession were grown in a growth chamber, as described by Paul and Hartman (2009). At the V3 to V4 stage of development, fully expanded leaves were collected and rinsed four to five times in autoclaved distilled water. These were briefly air dried and then transferred to sealable, clear plastic "clamshell" containers ( 21 by 13 by $3 \mathrm{~cm}$ ) of the type designed to display items for retail sale. Each container had a moistened, autoclaved paper towel in the bottom to maintain a high humidity level. Inoculum used for this experiment was prepared using the same method that we used for the greenhouse study. Individual leaflets were placed adaxial side down on the moistened towels and the abaxial sides were inoculated until runoff occurred. Individual leaflets were labeled with 9-mm Tough-Spots round, adhesive colored labels (Diversified Biotech, Dedham, MA, U.S.A.) so that multiple genotypes could be assayed in the same container. The detached leaflets were then inoculated using a Paasche airbrush as described for the greenhouse seedling assay. The containers were sealed and placed in a growth chamber, where they were maintained for 2 weeks at 20 to $23^{\circ} \mathrm{C}$ and under a photoperiod of $12 \mathrm{~h}$ of light and $12 \mathrm{~h}$ of darkness. For $24 \mathrm{~h}$ after inoculation, the culture containers were covered with aluminum foil to shade the urediniospores in order to promote infection of the plant tissue.

Infection type was determined and disease severity was rated using the same 1-to-5 scale used in the greenhouse assays. Four $1.0-\mathrm{cm}^{2}$ circles were marked and the number of lesions in each was counted as had been done in the greenhouse assays. The circles were then excised from each leaflet using a cork borer and the discs were transferred to one well in a 24-well plate with a flat bottom and a low evaporation lid. The discs were bathed for $24 \mathrm{~h}$ in a $3: 1$ (vol/vol) solution of absolute ethanol and acetic acid to fix and clear the tissue of chlorophyll and other pigments (Bonde et al. 2006; Paul and Hartman 2009). The discs were then transferred to lactophenol for $24 \mathrm{~h}$ to further clear the tissue, and urediniospores were subsequently stained with $0.1 \%$ cotton blue in lactophenol for $24 \mathrm{~h}$. After the leaf tissue was rinsed twice with distilled water, the stained uredinia were counted at $\times 100$ magnification. The number of uredinia per lesion was then determined by dividing the number of uredinia on a leaf disc by the number of SBR lesions. Plant reactions were considered to be resistant if inoculated leaves had no visible lesions or had RB lesions with an average number of uredinia per lesion that was significantly lower than the numbers on the susceptible checks.
Statistical analyses. Quantitative data were analyzed for statistically significant differences using PROC MIXED in SAS (SAS Institute, Cary, NC, U.S.A.). Data were first tested for heterogeneity of error variances and transformed prior to analysis of variance and means separation if necessary. In the case of the severity scores, a square-root transformation was used and, for the lesion and uredinia density data, the log to the base 10 was used after the addition of 1 to each data point. After confirmation that there were significant differences among the treatment means based on Fisher's protected least significant difference (LSD) $(P \leq 0.05)$, the transformed means were separated based on the LSD. Transformed data means were later back-transformed to obtain the values presented in the tables. For the data from the detached-leaf study, a Pearson correlation coefficient analysis was conducted on the disease severity ratings, the counts of uredinia per square centimeter made on the live tissue, and the uredinia counts made on the cleared tissue.

\section{Results}

Greenhouse experiment. Infection type (i.e., IM, RB, or TAN) reactions and mean numbers of uredinia per lesion from the greenhouse experiment are shown in Table 2, where they are listed in order of increasing uredinia numbers, averaged across the six isolates. Rpp genes and resistance alleles are included in Table 2 if known, though the Rpp genes in many of the PIs were not yet known when the experiments were begun. Although disease severity ratings and numbers of lesions per square centimeter were often higher for lines with TAN reactions (Supplementary Tables S1 and S2), the number of uredinia per lesion was a more informative indicator of resistance and the reproduction potential of each isolate on a specific host genotype. For example, the numbers of lesions per square centimeter in $\mathrm{RB}$ and TAN lesions induced by the FL11-Q isolate were often similar (Supplementary Table S2), whereas all but one of the soybean lines that developed RB infection types averaged 1.1 or fewer uredinia per lesion (Table 2). The mean number of uredinia per RB lesion in this experiment was $0.17 \pm 0.28$ (standard error [SE]), compared with an average of $2.15 \pm 0.42$ (SE) uredinia in TAN lesions. The exception, PI 417089A, averaged 1.3 uredinia per RB lesion caused by the LA09-BC isolate. PI 417089B leaves infected with the FL12-Q isolate also averaged 1.3 uredinia per lesion but the infection type was considered to be TAN due to a greater abundance of urediniospores. The average number of uredinia per lesion in TAN lesions for specific soybean-isolate combinations ranged from 1.3 to 3.6.

Because soybean PI-SBR isolate interactions had a significant $(P \leq 0.05)$ effect on the quantitative disease ratings, the quantitative disease reactions to each isolate were analyzed separately. The 2011 and 2012 isolates from Quincy, FL were more virulent than the 2009 isolate from Quincy or the 2008 and 2009 isolates from Alabama and Louisiana (Table 2; Supplementary Tables S1 and S2). The FL12-Q isolate was the most virulent and aggressive isolate, causing a TAN reaction on 33 of 41 PIs (80\%), and on nine accessions that had RB reactions to the FL11-Q isolate, which induced a TAN reaction on 24 of the PIs (Table 2).

All of the cultivars and elite lines used as susceptible checks (Williams 82, LD00-2817P, R00-1194F, and 5601T) developed TAN reactions to all of the six $P$. pachyrhizi isolates (Table 2). Across isolates, the checks had 2.30 to 2.85 uredinia/SBR lesion. In contrast, 32 of the other 41 entries averaged less than 1.0 uredinium/lesion. The reactions of the lines that were included as differentials (i.e., accessions whose Rpp gene locations were known at the time the assays were conducted) were highly variable. PI 471904 and PI 506764 (Hyuuga) were the only accessions from the differential set that had an $\mathrm{RB}$ reaction to all six isolates. The former has a resistance allele at the Rpp 5 locus and Hyuuga has Rpp 3 and a second resistance allele at the Rpp 5 locus. The Rpp6 gene in PI 567102B provided a high level of resistance to all of the isolates except FL12-Q, while Rpp1 (PI 200492), Rpp2 (PI 230970), Rpp3 (PI 462312), and $R p p 7$ (PI 605823) provided resistance to all of the isolates except the 2011 and 2012 isolates from Florida (Table 2). At the time the plants were inspected ( 2 weeks postinoculation), no SBR 
symptoms were visible on PI 200492 plants challenged with the FL09-Q isolate. In contrast, the Rpp1-b gene in PI 594538A and the allele at the Rppl locus in PI 587880A did not confer resistance to any of the isolates, and the Rpp 4 gene from PI 459025B also provided little or no resistance to any of the isolates. Like PI 200492, PI 416826A did not develop any macroscopically visible lesions when challenged with the FL09-Q isolate.

Three differentials known to have a resistance allele at the Rpp5 locus had different reaction patterns to the six isolates (Table 2). Although PI 471904 had RB reactions to all of the isolates, the recessive rpp5 allele from PI 200456 conferred resistance to only the
Alabama and Louisiana isolates. PI 200526, which has a dominant allele at the Rpp5 locus, was susceptible to all six isolates. PI 567102B (Rpp6) had RB reactions to all of the isolates except FL12-Q. PI 605823 , which carries the $R p p 7$ gene recently discovered by Childs et al. (2018b), was resistant to all of the 2008 and 2009 isolates but had TAN reactions to the FL11-Q and FL12-Q isolates.

PI 224268, PI 567025A, PI 567039, PI 567046A, and the Vietnamese cultivar DT 2000 (PI 635999) developed RB reactions to all six isolates, whereas PI 203398, PI 417208, PI 567129, PI 567189A, PI 605773, PI 605791A, PI 605854B, PI 605891A, and PI 606440A had resistance to all of the isolates except for FL12-Q

Table 2. Infection type and average number of uredinia per lesion on 41 soybean germplasm accessions (plant introductions [PIs]) and four susceptible checks challenged with six Phakopsora pachyrhizi (soybean rust) isolates from locations in the southern United States in greenhouse seedling assays ${ }^{\mathrm{a}}$

\begin{tabular}{|c|c|c|c|c|c|c|c|c|c|c|}
\hline Line & Resistance genes $^{b}$ & Comments & AL08-FH & AL09-FH & LA09-BC & FL09-Q & FL11-Q & FL12-Q & Meanc & SE $^{\mathbf{d}}$ \\
\hline PI 567025A & $(R p p 3)$ & $\ldots$ & 0.0 & 0.0 & 0.0 & 0.0 & 0.1 & 0.4 & 0.08 & 0.07 \\
\hline PI 506764 & Rpp3 + Rpp 5 allele & Hyuuga & 0.0 & 0.0 & 0.0 & 0.0 & 0.0 & 0.7 & 0.12 & 0.12 \\
\hline PI 567046A & $(R p p 3)$ & $\ldots$ & 0.0 & 0.0 & 0.0 & 0.0 & 0.2 & 0.6 & 0.13 & 0.10 \\
\hline PI 567039 & $(R p p 3)$ & $\ldots$ & 0.0 & 0.0 & 0.0 & 0.0 & 0.1 & 0.8 & 0.15 & 0.13 \\
\hline PI 635999 & Rpp3 + Rpp 4 allele & DT 2000 & 0.2 & 0.0 & 0.0 & 0.0 & 0.2 & 0.5 & 0.15 & 0.08 \\
\hline PI 471904 & Rpp5 allele & Differential & 0.0 & 0.0 & 0.0 & 0.1 & 0.1 & 1.1 & 0.22 & 0.18 \\
\hline PI 224268 & Unknown & $\ldots$ & 0.0 & 0.1 & 0.1 & 0.0 & 0.5 & 1.1 & 0.30 & 0.18 \\
\hline PI 203398 & Unknown & $\ldots$ & 0.0 & 0.0 & 0.0 & 0.0 & 0.2 & 1.9 & 0.35 & 0.31 \\
\hline PI 605854B & (Rpp3) & $\ldots$ & 0.0 & 0.0 & 0.0 & 0.0 & 0.3 & 1.9 & 0.37 & 0.31 \\
\hline PI 567102B & Rpp6 & Differential & 0.0 & 0.1 & 0.0 & 0.0 & 0.1 & 2.0 & 0.37 & 0.33 \\
\hline PI 417208 & Unknown & $\ldots$ & 0.0 & 0.0 & 0.0 & 0.0 & 0.3 & 2.0 & 0.38 & 0.33 \\
\hline PI 605773 & Unknown & $\ldots$ & 0.0 & 0.0 & 0.0 & 0.0 & 0.3 & 2.0 & 0.38 & 0.33 \\
\hline PI 567189A & Unknown & $\ldots$ & 0.0 & 0.0 & 0.0 & 0.0 & 0.3 & 2.1 & 0.40 & 0.34 \\
\hline PI 605891A & (Rpp3) & $\ldots$ & 0.0 & 0.0 & 0.0 & 0.0 & 0.3 & 2.1 & 0.40 & 0.34 \\
\hline PI 605865B & (Rpp3) & $\ldots$ & 0.0 & 0.0 & 0.0 & 0.0 & 1.6 & 1.9 & 0.58 & 0.37 \\
\hline PI 417503 & (Rpp3) & $\ldots$ & 0.0 & 0.0 & 0.0 & 0.0 & 1.7 & 2.0 & 0.62 & 0.39 \\
\hline PI 567129 & (Rpp6) & $\ldots$ & 0.3 & 0.0 & 0.0 & 0.4 & 0.5 & 2.5 & 0.62 & 0.39 \\
\hline PI 416826A & (Rpp3) & $\ldots$ & 0.0 & 0.0 & 0.0 & 0.0 & 1.9 & 2.0 & 0.65 & 0.41 \\
\hline PI 567104B & (Rpp6) & $\ldots$ & 0.0 & 0.2 & 0.0 & 0.0 & 1.7 & 2.0 & 0.65 & 0.38 \\
\hline PI 417132 & (Rpp3) & $\ldots$ & 0.1 & 0.0 & 0.0 & 0.0 & 1.7 & 2.4 & 0.70 & 0.44 \\
\hline PI 605885B & (Rpp3) & $\ldots$ & 0.0 & 0.0 & 0.0 & 0.0 & 1.7 & 2.7 & 0.73 & 0.48 \\
\hline PI 606405 & (Rpp3) & $\ldots$ & 0.0 & 0.0 & 0.1 & 0.0 & 1.7 & 2.6 & 0.73 & 0.46 \\
\hline PI 417125 & Unknown & $\ldots$ & 0.1 & 0.6 & 0.5 & 0.1 & 1.4 & 1.8 & 0.75 & 0.29 \\
\hline PI 605838 & (Rpp3) & $\ldots$ & 0.0 & 0.0 & 0.0 & 0.0 & 1.8 & 2.7 & 0.75 & 0.49 \\
\hline PI 606440A & Unknown & $\ldots$ & 0.0 & 0.6 & 0.5 & 0.6 & 0.4 & 2.4 & 0.75 & 0.34 \\
\hline PI 615437 & (Rpp3) & $\ldots$ & 0.0 & 0.4 & 0.0 & 0.0 & 1.7 & 2.4 & 0.75 & 0.43 \\
\hline PI 230970 & Rpp2 & Differential & 0.3 & 0.1 & 0.5 & 0.9 & 1.3 & 1.5 & 0.77 & 0.23 \\
\hline PI 605791A & (Rpp4) & $\ldots$ & 0.6 & 0.5 & 1.0 & 0.3 & 0.4 & 1.8 & 0.77 & 0.23 \\
\hline PI 417089B & $($ Rpp3)? & $\ldots$ & 0.2 & 0.4 & 0.0 & 0.0 & 2.7 & 1.3 & 0.77 & 0.43 \\
\hline PI 417089A & (Rpp3) & $\ldots$ & 0.2 & 0.0 & 1.3 & 0.0 & 2.3 & 0.9 & 0.78 & 0.37 \\
\hline PI 462312 & Rpp3 & Differential & 0.1 & 0.1 & 0.0 & 0.3 & 2.0 & 2.7 & 0.87 & 0.48 \\
\hline PI 200492 & Rppl & Differential & 0.7 & 0.2 & 0.1 & 0.0 & 1.8 & 2.5 & 0.88 & 0.42 \\
\hline PI 605823 & $R p p 7$ & Differential & 1.1 & 0.6 & 1.0 & 0.6 & 1.7 & 2.5 & 1.25 & 0.30 \\
\hline PI 200456 & rpp5 & Differential & 0.4 & 0.4 & 0.5 & 2.2 & 2.1 & 2.4 & 1.33 & 0.40 \\
\hline PI 459025B & Rpp4 & Differential & 1.5 & 1.6 & 2.1 & 1.5 & 2.0 & 2.3 & 1.83 & 0.14 \\
\hline PI 567351B & Unknown & $\ldots$ & 1.5 & 2.0 & 2.0 & 1.9 & 2.0 & 2.3 & 1.95 & 0.11 \\
\hline PI 200526 & Rpp5 allele & Differential & 1.9 & 1.9 & 1.9 & 1.9 & 2.2 & 2.5 & 2.05 & 0.10 \\
\hline PI 594538B & $R p p 1-b$ & Differential & 1.9 & 1.7 & 2.2 & 1.9 & 2.3 & 2.5 & 2.08 & 0.12 \\
\hline PI 567056B & $(R p p 3)$ & $\ldots$ & 2.2 & 2.0 & 2.3 & 1.9 & 2.1 & 2.3 & 2.13 & 0.07 \\
\hline PI 470227B & Unknown & $\ldots$ & 2.3 & 2.0 & 2.7 & 1.9 & 1.7 & 2.3 & 2.15 & 0.15 \\
\hline LD00-2817P & None & Check & 2.1 & 2.3 & 2.5 & 1.6 & 2.5 & 2.8 & 2.30 & 0.17 \\
\hline PI 587880A & Rppl allele & Differential & 2.7 & 3.1 & 2.0 & 2.0 & 1.9 & 2.1 & 2.30 & 0.20 \\
\hline R00-1194F & None & Check & 2.3 & 2.1 & 2.5 & 2.2 & 2.4 & 2.6 & 2.35 & 0.08 \\
\hline $5601 \mathrm{~T}$ & None & Check & 3.4 & 2.0 & 2.3 & 2.2 & 2.4 & 2.7 & 2.50 & 0.20 \\
\hline Williams 82 & None & Check & 2.6 & 2.4 & 2.5 & 2.8 & 3.2 & 3.6 & 2.85 & 0.19 \\
\hline $\operatorname{LSD}(0.05)^{\mathrm{e}}$ & $\ldots$ & $\ldots$ & 0.88 & 0.64 & 0.96 & 0.55 & 0.86 & 0.85 & 0.79 & $\ldots$ \\
\hline
\end{tabular}

a Infection type is indicated by bold, italics, or roman type and numerical values represent the mean number of uredinia per lesion that developed on seedlings of a soybean line inoculated with a specific fungal isolate. Host-inoculum combinations that resulted in a reddish-brown resistance infection type are in italics and those resulting in a TAN susceptibility infection type are in bold. Combinations that produced no macroscopically visible disease symptoms are in roman. $R p p$ resistance genes are listed if known, and lines used as differentials are indicated.

$\mathrm{b}$ Gene names in parentheses indicate genomic locations of resistance alleles that may or may not be the same allele as the original gene given that name.

${ }^{c}$ Means are the number of uredinia per lesion averaged across the six isolates.

d Standard error.

e Least significant difference. 
(Table 2). Ten other accessions were resistant to the 2008 and 2009 isolates but were susceptible to the Florida isolates from 2011 and 2012. PI 417089A, which is now known to have a resistance allele at the Rpp3 locus, was unique among the lines tested in having a TAN reaction to the FL11-Q isolate but an RB reaction to FL12-Q. The closely related accession PI 417089B was rated as having a TAN reaction to the 2011 and 2012 Florida isolates but the number of uredinia per lesion from infection with FL12-Q was not significantly higher than the number in the RB lesions of PI 417089A. Although PI 417089A had an RB reaction to LA09-BC, the lesions had an unusually high number of uredinia compared with other lines with $\mathrm{RB}$ lesions. Among the 10 PIs that were resistant to all of the isolates except FL11-Q and FL12-Q, PI 416826A was unique in having no visible reaction to the FL09-Q isolate at the time ratings were done (Table 2).

Fifteen accessions had RB reactions to the Alabama and Louisiana isolates and no visible uredinia resulting from infection by those three isolates (Table 2). PI 567025A, PI 567039, PI 567046A, PI 203398, PI 417208, PI 567189A, PI 605773, PI 605854B, PI 605891A, PI 417503, PI 605838, PI 605865B, PI 605885B, PI 416826A, and PI 635999 had similarly high levels of resistance to the 2009 isolate from Florida. Of these 15 PIs, 9 also had RB reactions to the FL11-Q isolate, though some of the lesions developed uredinia (Table 2). Accessions that averaged 0.2 or fewer uredinia per lesion from infection by only one or two of the 2008 and 2009 isolates included the differentials PI 471904 (allele of Rpp5) and PI 567102B (Rpp6) and the lines PI 224268, PI
417132, PI 567104B, and PI 606405. In contrast, PI 470227B, PI $567056 \mathrm{~B}$, and PI 567351B were susceptible to all six isolates, despite an allele at the Rpp3 locus in PI 567056A that provided resistance to some foreign P. pachyrhizi isolates (Harris et al. 2015).

Averaged across the six isolates, these susceptible PIs had 1.95 to 2.15 uredinia per lesion.

PI 605854B and PI 605891A have a resistance gene at the Rpp3 locus, PI 605791A has a gene at the Rpp4 locus, and PI 567129 has a gene at the Rpp6 locus (Harris et al. 2015). The locations of the resistance genes in PI 203398, PI 417208 567189A, PI 605773 , and PI 606440A have not yet been reported. Although these nine accessions had TAN reactions to the FL12-Q isolate, seven averaged 2.1 or fewer uredinia per lesion compared with 2.6 to 3.6 for the four susceptible checks.

Overall, the average number of uredinia per lesion was 2.0 or higher on most leaves that developed TAN lesions, and was usually less than 1.0 on most of those with RB lesions (Table 2). Many RB lesions had no visible uredinia 2 weeks after inoculation. Only four host-isolate combinations resulted in RB lesions that averaged more than 1.0 uredinium/lesion.

Detached-leaf experiment. Infection type and average number of uredinia per lesion data from the detached-leaf assays are presented in Table 3 in order of increasing numbers of uredinia per lesion, averaged across the six isolates, and disease severity rating and lesion density data are provided in Supplementary Tables S3 and S4. Twelve PIs screened in this experiment were not included in the greenhouse experiment but the reactions of all of the soybean

Table 3. Infection type and average number of uredinia per lesion on 27 germplasm accessions (plant introductions [PIs]), two susceptible checks, and one Rpp 1 isoline (L85-2378) challenged with six Phakopsora pachyrhizi (soybean rust) isolates from locations in the southern United States in detached-leaf assays ${ }^{\mathrm{a}}$

\begin{tabular}{|c|c|c|c|c|c|c|c|c|c|c|}
\hline Line & Rpp genes $^{\mathrm{b}}$ & Comments & AL08-FH & AL09-FH & LA09-BC & FL09-Q & FL11-Q & FL12-Q & Mean & $\mathbf{S E}^{\mathrm{c}}$ \\
\hline PI 471904 & Rpp5 & Differential & 0.2 & 0.0 & 0.1 & 0.1 & 0.0 & 1.0 & 0.23 & 0.16 \\
\hline PI 567046A & (Rpp3) & $\ldots$ & 0.1 & 0.0 & 0.0 & 0.0 & 0.4 & 1.0 & 0.25 & 0.16 \\
\hline PI 200487 & Rpp5 & Differential & 0.2 & 0.0 & 0.0 & 0.0 & 0.2 & 1.2 & 0.27 & 0.19 \\
\hline PI 567025A & (Rpp3) & $\ldots$ & 0.3 & 0.0 & 0.0 & 0.3 & 0.2 & 1.2 & 0.33 & 0.18 \\
\hline PI 635999 & $R p p 3+R p p 4$ & DT 2000 & 0.1 & 0.0 & 0.1 & 0.3 & 0.2 & 1.3 & 0.33 & 0.20 \\
\hline PI 567054C & $(R p p 3)$ & $\ldots$ & 0.3 & 0.0 & 0.0 & 0.0 & 0.2 & 1.7 & 0.36 & 0.27 \\
\hline PI 567024 & $($ Rpp4) & $\ldots$ & 0.0 & 0.1 & 0.1 & 0.0 & 0.5 & 1.8 & 0.40 & 0.28 \\
\hline PI 506764 & $R p p 3+R p p 5$ & Hyuuga & 0.0 & 0.1 & 0.0 & 0.3 & 0.7 & 1.5 & 0.44 & 0.24 \\
\hline PI 224268 & Unknown & $\ldots$ & 0.0 & 0.1 & 0.1 & 0.0 & 1.3 & 1.6 & 0.52 & 0.30 \\
\hline PI 567102B & Rpp6 & Differential & 0.0 & 0.0 & 0.1 & 0.0 & 0.6 & 2.5 & 0.54 & 0.40 \\
\hline PI 423960B & Unknown & $\ldots$ & 0.2 & 0.0 & 0.0 & 0.7 & 0.9 & 1.5 & 0.55 & 0.25 \\
\hline PI 417125 & Unknown & $\ldots$ & 0.0 & 0.2 & 0.0 & 0.3 & 1.6 & 1.7 & 0.63 & 0.33 \\
\hline PI 594796 & Unknown & $\ldots$ & 1.5 & 0.2 & 0.6 & 0.3 & 0.3 & 1.3 & 0.69 & 0.23 \\
\hline PI 423959 & Unknown & $\ldots$ & 0.6 & 0.1 & 0.0 & 0.0 & 1.2 & 2.3 & 0.70 & 0.38 \\
\hline PI 567056A & (Rpp3) & $\ldots$ & 0.0 & 0.0 & 0.1 & 1.0 & 1.3 & 1.9 & 0.72 & 0.33 \\
\hline PI 518295 & Unknown & $\ldots$ & 0.4 & 0.2 & 0.4 & 0.0 & 0.9 & 3.5 & 0.91 & 0.53 \\
\hline PI 567104B & (Rpp6) & $\ldots$ & 0.0 & 0.1 & 0.4 & 0.0 & 1.9 & 3.5 & 0.98 & 0.59 \\
\hline PI 200492 & Rpp1 & Differential & 0.4 & 0.1 & 0.2 & 0.0 & 2.4 & 2.9 & 1.00 & 0.53 \\
\hline L85-2378 & Rppl isoline & Differential & 0.0 & 0.3 & 0.3 & 0.0 & 2.0 & 3.4 & 1.01 & 0.57 \\
\hline PI 462312 & Rpp3 & Differential & 0.2 & 0.1 & 0.1 & 0.5 & 1.8 & 3.9 & 1.10 & 0.62 \\
\hline PI 417126 & Unknown & $\ldots$ & 0.6 & 0.5 & 1.4 & 1.4 & 1.6 & 1.9 & 1.21 & 0.22 \\
\hline PI 230970 & Rpp2 & Differential & 1.1 & 1.4 & 0.7 & 1.0 & 1.5 & 2.0 & 1.28 & 0.19 \\
\hline PI 605823 & Rpp 7 & Differential & 0.2 & 0.8 & 0.9 & 0.3 & 2.1 & 3.4 & 1.28 & 0.51 \\
\hline PI 416778 & Unknown & $\ldots$ & 0.5 & 1.2 & 1.5 & 1.8 & 2.0 & 1.6 & 1.43 & 0.21 \\
\hline PI 417129B & Unknown & $\ldots$ & 1.5 & 0.0 & 0.5 & 2.2 & 2.7 & 2.9 & 1.64 & 0.48 \\
\hline PI 506938 & Unknown & $\ldots$ & 1.1 & 2.3 & 2.3 & 1.1 & 2.0 & 2.7 & 1.91 & 0.28 \\
\hline PI 567046C & Unknown & $\ldots$ & 3.5 & 4.6 & 2.7 & 0.5 & 1.6 & 0.6 & 2.25 & 0.66 \\
\hline PI 459025B & Rpp4 & Differential & 2.6 & 1.2 & 3.7 & 2.2 & 2.4 & 2.6 & 2.44 & 0.33 \\
\hline LD00-3309 & None & Check & 2.2 & 2.0 & 3.2 & 2.9 & 3.6 & 4.1 & 3.00 & 0.33 \\
\hline Williams 82 & None & Check & 3.3 & 5.1 & 3.3 & 3.3 & 3.9 & 4.4 & 3.89 & 0.30 \\
\hline $\operatorname{LSD}(0.05)^{\mathrm{d}}$ & $\ldots$ & $\ldots$ & 0.13 & 0.10 & 0.10 & 0.07 & 0.08 & 0.11 & 0.10 & $\ldots$ \\
\hline
\end{tabular}

${ }^{a}$ Infection types are indicated by bold, italics, and roman type, and the numerical values represent mean numbers of uredinia per lesion that developed on seedlings of a soybean line challenged with a specific fungal isolate. Host-inoculum combinations that resulted in a reddish-brown resistance infection type are in italics and those resulting in a TAN susceptibility infection type are in bold. Combinations that produced no macroscopically visible disease symptoms are in roman $R p p$ resistance genes are listed if known, and the lines used as differentials are indicated.

${ }^{\mathrm{b}}$ Gene names in parentheses indicate genomic locations of resistance alleles that may or may not be the same allele as the original gene given that name.

c Standard error.

${ }^{\mathrm{d}}$ Least significant difference. 
accessions that were in both experiments were very similar. As in the greenhouse assays, differential reactions to the isolates were observed, often involving reactions to the 2011 and 2012 isolates from Florida. Averaged across the six isolates, the mean number of uredinia per lesion ranged from 0.23 on PI 471904 to 3.89 on Williams 82 (Table 3 ). The mean number of uredinia per RB lesion in this experiment was $0.36 \pm 0.04(\mathrm{SE})$, and TAN lesions averaged $2.38 \pm$ 0.09 (SE) uredinia/lesion.

The two susceptible checks, LD00-3309 and Williams 82, developed a TAN infection type to all six isolates (Table 3). Based on the number of uredinia per lesion, Williams 82 appeared to be more susceptible to the AL09-FH isolate than to the other isolates; however, because this was not observed in the greenhouse assays, it would need to be confirmed. Although LD00-3309 was susceptible to all of the isolates, it appeared to be somewhat less susceptible than Williams 82 to all of the isolates except LA09-BC based on uredinia counts. It even had fewer uredinia per lesion than PI 459025B (source of the Rpp 4 gene) when challenged with the Alabama and Louisiana isolates, and fewer than PI 567046 when both were challenged with the two Alabama isolates. Most of these differences were small but they were statistically significant.

Eight lines, including the differentials PI 200487, PI 471904, and Hyuuga (PI 506764), had an RB reaction to all of the isolates (Table 3). PI 200487 and PI 471904 both averaged 0.33 or fewer uredinia per lesion. Other highly resistant accessions included two lines with resistance alleles at the Rpp3 locus (PI 567046A and PI $567025 \mathrm{~A}$ ) and two whose resistance genes have not yet been reported (PI 224268 and PI 423960B). Three lines were resistant to all of the isolates except FL12-Q.

PI 200492 (Rpp1), PI 230970 (Rpp2), and PI 462312 (Rpp3) showed resistance to all of the isolates except FL11-Q and FL12-Q (Table 3). L85-2378, the Williams 82 isoline into which the Rppl gene had been introgressed from PI 200492, had the same reaction pattern as PI 200492, and had similar numbers of uredinia per lesion for each isolate. PI 200492 and L85-2378, along with PI 518295, did not develop any visible lesions when infected with the FL09-Q isolate, confirming the immunity or near-immunity of PI 200492 against this isolate in the greenhouse assays (Table 2). As in the greenhouse experiment, the Rpp4 gene of PI 459025B did not provide much resistance to any of the isolates, though it may have suppressed the number of uredinia per lesion somewhat on leaves infected with AL09-FH and the isolates from Florida. The Rpp5 resistance alleles of PI 200487 and PI 471904 conditioned $\mathrm{RB}$ reactions to all six isolates, as did the resistance alleles at the Rpp 3 and Rpp5 loci in Hyuuga (PI 506764). The Rpp6 gene in PI 567102B provided resistance to all of the isolates except FL12-Q, and PI 567102B plants challenged with that isolate averaged only 2.5 uredinia/lesion compared with 4.4 on Williams 82 and 4.1 on LD00-3309, indicating that resistance mediated by the Rpp6 gene had not been entirely overcome (Table 3). The Rpp7 gene in PI 605823 conditioned an RB reaction to all of the isolates except FL12-Q and FL11-Q. The reactions of differential lines observed in the detached-leaf assay thus corroborate those seen in the greenhouse assay.

Fourteen of the germplasm accessions evaluated using the detached-leaf assays had also been in the greenhouse resistance evaluations, including Hyuuga and six other differentials with known Rpp genes (Table 3). These included PI 567046A, PI 567025A, DT 2000 (PI 635999), PI 224268, PI 417125, PI 567104B, and PI 605823, all of which had resistance to the 2008 and 2009 isolates in both types of assays (Tables 2 and 3). PI 567046A, PI 567025A, and DT 2000, which were among the most resistant accessions tested in the greenhouse assays (Table 2), were also resistant to all of the isolates and had some of the lowest uredinia counts in the detached-leaf assays (Table 3). PI 567025A and PI 567046A are now known to carry a resistance allele at the Rpp 3 locus, and there has been speculation that PI 423960B might have more than one resistance gene (Harris et al. 2015). PI 417125, PI 567104B, and PI 605823 (Rpp7) were resistant to all of the isolates except FL11-Q and FL12-Q, and had the same infection type reaction patterns as they had in the greenhouse experiment. PI 423959 and PI 567056A were also resistant to all of the isolates except FL11-Q and FL12-Q but had not been tested in the greenhouse experiment. Of the accessions in this experiment that were not included in the greenhouse assays, PI 518295 and PI 567024 (Rpp4 allele) and PI 567054C (Rpp3 allele) were resistant to all isolates except FL12-Q (Supplementary Tables S3 and S4).

Several of the accessions assayed had unusual or unexpected patterns of reaction to the six isolates. PI 416778 had an RB reaction to the two Alabama isolates and, surprisingly, to the FL12-Q isolate but was susceptible to the other isolates (Table 3). PI 417126, PI 594796, PI 417129B, and PI 506938 each had unique reaction patterns to the six isolates. All had a TAN reaction to the FL12-Q isolate but variable reactions to the other isolates. The reactions of PI $567046 \mathrm{C}$ were particularly unusual and were very different from the reactions of the PI 567046A subline, which was highly resistant in the greenhouse and detached-leaf experiments. The PI 567046C subline developed a TAN reaction to all of the isolates except the FL12-Q and FL09-Q isolates, even though FL12-Q was the most virulent and aggressive of the six isolates. In contrast, the "A" subline developed an RB response to all six isolates in the greenhouse experiment and in the detached-leaf assays (Tables 2 and 3). It is possible that 567046A has an Rpp gene that is absent in PI $567046 \mathrm{C}$. Because of the level of sporulation observed on it, PI 594796 was classified as having a TAN reaction to $12 \mathrm{FL}-\mathrm{Q}$, even though it had fewer uredinia per lesion than some other accessions that had $\mathrm{RB}$ reactions (Table 3 ).

Correlations between severity and uredinia counts based on live tissue $(r=0.45, P<0.0001)$ and fixed tissue $(r=0.46, P<0.0001)$ were significant for the accessions in the detached-leaf assay. There was a much stronger correlation $(r=0.98, P<0.0001)$ between the uredinia counts made on live tissue and fixed tissue, indicating that the tissue clearing and staining procedure should not be necessary for evaluating SBR resistance and selecting SBRresistant plants and lines. The uredinia per lesion counts in the detached-leaf assays were higher. A higher inoculum dosage or more favorable germination conditions for urediniospores may have contributed to this.

Phakopsora pachyrhizi isolate pathotypes. Variation in the reactions of the soybean PIs in this study show that the six P. pachyrhizi isolates represented different pathotypes. The differential reactions of the soybean lines to different isolates suggest temporal and more subtle geographical differences in pathogenicity. Although the reactions of the PIs assayed in the greenhouse suggested that the 2008 and 2009 isolates shared similarities in their pathotypes, the differential reactions of lines such as PI 416778, PI 417129B, and PI 506938 in the detached-leaf study suggested some pathotype differences among those isolates (Table 3 ). In the greenhouse assays, PI 200456 (rpp5) had RB reactions to the Alabama and Louisiana isolates but developed a TAN reaction and more uredinia per lesion from the FL09-Q isolate (Table 2). The unusual and unexpected reaction patterns of PI 416778, PI 417126, PI 417129B, PI 506938, PI 567046C, and PI 594796 to the 2008 and 2009 isolates in the detached-leaf experiment, however, revealed differences in pathogenicity. None of these six informative accessions had been evaluated in the greenhouse experiment.

The FL12-Q isolate was more virulent than the 2009 and 2011 isolates from Florida, inducing TAN reactions on $80 \%$ of the accessions tested compared with 59\% for FL11-Q and 30\% for FL09-Q (Tables 2 and 3). The virulence of the FL11-Q isolate was intermediate between those of the FL09-Q and FL12-Q isolates. It was similar to FL12-Q in being able to produce a TAN reaction on the PIs with the Rpp 2 and Rpp 3 genes and 11 other accessions in the greenhouse experiment but was less virulent than FL12-Q on 9 accessions (Table 2). As had been the case in the reactions to the Alabama and Louisiana isolates, the reactions of PI 416778, PI 417129B, PI 506938, and PI 594796 indicated differences in pathogenicity among the Florida isolates in the detached-leaf assays (Table 3).

In the greenhouse experiment, the uredinia per lesion counts on the four susceptible checks indicated that there were no large differences 
in the aggressiveness of the six isolates, though the FL12-Q isolate induced the highest or second highest number of uredinia per lesion on each of the checks (Table 2). This was also true in the detachedleaf experiment, though the AL09-FH isolate induced the highest number of uredinia per lesion on Williams 82 (Table 3). Differences in the reactions of susceptible cultivars within each experiment and in the numbers of lesions counted on Williams 82 in the two experiments indicated that additional data would be needed to confirm any possible differences in aggressiveness.

\section{Discussion}

This study provided new information about (i) the resistance of 44 germplasm accessions to a panel of diverse P. pachyrhizi (SBR) isolates representing four growing seasons and three geographical locations, (ii) allelic diversity among accessions that have resistance gene alleles at the same Rpp locus, (iii) the efficacy of natural Rpp gene pyramids in Hyuuga (PI 506764) and DT 2000 (PI 635999), and (iv) pathotype diversity among the six P. pachyrhizi isolates used. The soybean lines tested were either PIs with known Rpp genes, which were included as differentials, or PIs that had resistance in field tests in the southern United States (Walker et al. 2011, 2014a,b). Pathogenic variation among the six P. pachyrhizi isolates was manifested as differences in infection type (i.e., TAN, $\mathrm{RB}$, or IM) and as quantitative variation in the numbers of uredinia per SBR lesion. The germplasm accessions that were assayed in both the greenhouse and detached-leaf experiments had similar reactions in both. The higher uredinia per lesion counts in the detached-leaf assays were due, in part, to the fact that clearing and staining the leaves made uredinia on both sides of a leaf visible. Developing uredinia that might not have been visible on a live leaf might have also been distinguishable. Although we have focused on infection type and differences in the number of uredinia per lesion in the text, severity ratings were almost always higher for soybean PIs with TAN reactions and higher lesion densities (Supplementary Tables S1 through S4).

Resistance to $P$. pachyrhizi has often been assessed primarily on the basis of infection type but, as Shaner et al. (1992) pointed out, virulence can be complex. Bromfield (1984) suggested that the RB and TAN infection types should be subdivided on the basis of the number of uredinia per lesion and the amount of sporulation, and other researchers have developed more precise reaction classification criteria for SBR lesions (Miles et al. 2011; Yamanaka et al. 2010). In the present study, we regarded uredinia per lesion to be an important measurement of resistance based on the conclusions of Yamanaka et al. (2010) and Miles et al. (2011). However, infection type (i.e., lesion color) was generally a reliable indicator of the average number of uredinia per lesion, and could be determined much more rapidly than uredinia per lesion counts.

The results of the experiments confirmed that PIs with resistance genes at the same Rpp locus or genomic region can have very different reactions to certain isolates of $P$. pachyrhizi. The more resistant lines most likely have either a different allele at the same $R p p$ locus or an additional undetected Rpp gene that contributes to their resistance. The results also confirmed that there was pathotype diversity among the six isolates used in this study, particularly between the more virulent FL11-Q and FL12-Q isolates and the four less virulent isolates from 2008 and 2009.

At the time this study was conducted, the SBR resistance genes in many of the PIs assayed in these experiments had not yet been mapped but, since then, the identities and locations of Rpp genes in many of the genotypes have been reported. PI 605823 is of particular interest, because it is now known to carry the $\operatorname{Rpp} 7$ at a previously unreported locus on chromosome (Chr) 19 (Childs et al. 2018b). Many of the accessions genotyped by Harris et al. (2015) have a resistance gene at the Rpp 3 locus based on bulked segregant analysis, and resistance genes in other lines that were tested have been mapped to the Rpp4, Rpp6, or Rpp3 and Rpp4 loci (Harris et al. 2015).

Resistance genes at the Rppl locus on Chr 18 were represented in the greenhouse experiment by PI 200492 (Rppl), PI 594538B (Rppl-b), and PI 587880A. Although the Rppl gene of PI 200492 was initially effective against South American populations of $P$. pachyrhizi, the resistance was overcome by some fungal populations within two growing seasons after the appearance of SBR in Brazil (Ribeiro et al. 2007). PI 200492 and PI 547875 (L85-2378), a Williams 82 isoline with the same Rppl allele, were resistant to $P$. pachyrhizi field populations in the southern United States in multiple locations and growing seasons but they were susceptible to the 2012 population in Quincy, FL (Walker et al. 2011, 2014a). At least one pathotype in that field population, from which the FL12-Q isolate was purified, had the ability to reproduce vigorously on both PI 200492 (Rppl) and PI 567102B (Rpp6), lines which have historically had high levels of resistance to many U.S. fungal populations and isolates (Paul et al. 2013; Walker et al. 2011, 2014a,b). Although resistance conditioned by the Rpp1 gene from PI 200492 was overcome by the 2011 and 2012 isolates from Quincy, FL, in the present study, it was effective against field populations and isolates from the same location in subsequent growing seasons (unpublished data). In contrast to the Rppl gene from PI 200492, the Rppl-b gene of PI 594538 and the Rppl allele in PI 587880A have not provided any resistance to $P$. pachyrhizi populations in the United States, despite being effective against $P$. pachyrhizi isolates and populations in South America (Ray et al. 2009).

Harris et al. (2015) found that 52 of 75 PIs with SBR resistance in the United States have a resistance gene in the Rpp3 region on $\mathrm{Chr} 6$, and at least 19 of the lines evaluated in the present study are thought to have a resistance gene at the Rpp3 locus. Moreover, Hyuuga (PI 506764) and DT 2000 (PI 635999) have a resistance gene at the Rpp3 locus in addition to a second Rpp gene at a different locus. The lines from this study that carry an Rpp 3 resistance allele can be classified into four groups: (i) those that were resistant to all six isolates (based on having RB lesions with few or no uredinia), (ii) those that were resistant to all of the isolates except FL12-Q, (iii) those resistant to all of the 2008 and 2009 isolates but not to FL11-Q or FL12-Q, and (iv) those that were susceptible to all of the isolates. Five of the most resistant lines in the greenhouse assays, including Hyuuga and DT 2000 , have a resistance allele at the Rpp3 locus, and five of the eight most resistant lines in the detached-leaf assays also have an Rpp3 resistance allele. It remains unclear whether PI 567025A, PI 567039, PI 567046A, and PI 567054C possess an allele of the Rpp3 gene that is more effective in recognizing U.S. isolates of $P$. pachyrhizi than the "original" Rpp3 gene of PI 462312, or if they carry an additional unreported Rpp gene at another locus. PI 567025A, PI 567039, and PI $567046 \mathrm{~A}$ all originate from Indonesia; therefore, it is possible that they have the same allele of Rpp3. The second group of lines from the greenhouse experiment included PI 605854B and PI 605891A, and the third group, which was the largest, included PI 462312 (source of the original Rpp3 gene) and at least eight other PIs. PI 567056A was only in the detached-leaf experiment but its reaction pattern was like that of PI 462312. This was particularly interesting because, in the greenhouse experiment, the closely related accession PI $567056 \mathrm{~B}$ was the only line with a resistance gene at the Rpp3 locus that was susceptible to all six isolates.

The extent to which the second Rpp gene in Hyuuga and DT 2000 contributes to their resistance to U.S. isolates of $P$. pachyrhizi is also unclear. In some previous investigations, resistance segregation ratios and genetic mapping analyses of both lines suggested that the Rpp3 allele was responsible for most of their resistance (Monteros et al. 2007; Vuong et al. 2016). For both lines, phenotypic data for the reactions to $P$. pachyrhizi isolates from other countries were key to revealing the presence of a second Rpp gene. DT 2000 (PI 635999) is a cultivar from Vietnam with SBR resistance genes at the Rpp3 and Rpp4 loci (Vuong et al. 2016). The effect of the Rpp4 gene was detected using SBR disease data from Hanoi, Vietnam, but was not significantly associated with resistance in Quincy, FL. In the present study, the allele of the Rpp4 gene in PI 459025B may have slowed uredinium development from some isolates but it did not prevent the development of a TAN reaction to any of the isolates in either experiment. PI 459025B has also shown little or no resistance to U.S. populations of P. pachyrhizi in the field (Walker et al. 
2011, 2014a). In contrast, the Rpp4 allele from PI 605791A conditioned RB reactions to every isolate except FL12-Q in the greenhouse study. The availability of this effective allele from PI 605791A thus adds another locus to the possible combinations of Rpp genes that could be pyramided together to enhance the durability of SBRresistant soybean cultivars in the southern United States (Yamanaka et al. 2013).

The different patterns of reaction of PI 200456, PI 200526, and PI 471904 to the isolates in the greenhouse assays support the conclusion of Garcia et al. (2008) that these accessions have three different alleles at the Rpp5 locus. The allele in PI 471904 provided a high level of resistance to all six isolates in both experiments, as did the allele from PI 200487 in the detached-leaf experiment. In contrast, the recessive rpp5 allele in PI 200456 provided resistance against the isolates from Alabama and Louisiana but not against any of the Florida isolates. It was the only one of the PIs tested that had that particular reaction pattern. Although the allele from PI 200526 was not effective against any of the isolates in this study, it conditioned resistance to some South American isolates (Akamatsu et al. 2013). The Rpp 5 alleles from PI 471904 and PI 200487 would be of value for breeding SBR-resistant cultivars.

The Rpp6 gene from PI 567102B discovered by Li et al. (2012) provided a high level of resistance to all of the isolates except FL12-Q in both experiments, and this PI has also shown consistent resistance to SBR in field evaluations (Walker et al. 2011, 2014a). Although PI 567102B and PI 567104B originate from the same research station in Indonesia, resemble one another morphologically, and have had very similar levels of resistance to field populations of $P$. pachyrhizi (Walker et al. 2014a), it is still not known whether they have the same allele at the Rpp6 locus. Liu et al. (2016) mapped an SBR resistance gene in PI 567104B to the Rpp6 locus, and Harris et al. (2015) found evidence for a second resistance gene at the Rpp4 locus in PI 567104B, though that was never confirmed. If PI 567104b has another Rpp gene and the same Rpp6 allele as PI 567102B, it would be expected to be at least as resistant as PI 567102B; however, in the present study, PI 567102B was resistant to the FL11-Q isolate in both the greenhouse and detached-leaf assays, whereas PI 567104B was not. Song et al. (2015) reported some genetic dissimilarity between PI 567102B and PI 567104 in the Rpp6 region of Chr 18; thus, it is possible that the alleles in the two accessions are similar but not identical. PI 567129, another accession from East Java in Indonesia, also has a resistance gene at the Rpp6 locus (Harris et al. 2015). In the greenhouse assays, it had a reaction pattern identical to that of PI 567102B, suggesting that it may have the same Rpp6 allele. In both experiments, the Rpp7 gene that Childs et al. (2018b) mapped on Chr 19 conferred resistance to all of the isolates except the 2011 and 2012 isolates from Florida. Because this gene is located at a unique locus, it could be useful for developing unique $R p p$ gene pyramids to obtain more durable resistance to P. pachyrhizi.

The genes responsible for the resistance of two accessions with resistance to all six isolates are not yet known. PI 224268 (Asomasari), a maturity group VIII accession from the southern Japanese island of Kyūshū (Konno 1970), had an RB reaction to all of the isolates and had low uredinia counts in both experiments. PI 423960B (Gokudaizu), also from Kyūshū, was not tested in the greenhouse experiment but it had good resistance in the detached-leaf assays. The Rpp genes responsible for the resistance of PI 203308, PI 417125, PI 417208, PI 423959, PI 423960B, PI 594796, and PI 605773 are also still unknown. Therefore, mapping of the resistance genes in the most resistant of the PIs from the present study should be a research priority. Six of the nine PIs that were only susceptible to FL12-Q in the greenhouse assays originate from northern Vietnam, while PI 417208 is another accession from Kyūshū, Japan. PI 203398 is a 1952 cultivar from Brazil named Abura. Most of these nine PIs had been screened in a 2011 field test planted in Quincy, FL and in 2012 field tests in Quincy and in Attapulgus, GA. In both years, the $P$. pachyrhizi populations in Florida caused considerably more disease on PIs than the 2012 population in Georgia (Walker et al. 2014a). PI 203398, PI 417208, and PI 567129 were susceptible to the Florida populations in both years, whereas PI 605773, PI605791A, PI 605854B, and PI 605891A, all of which originate from Vietnam, had less disease in 2011 than in 2012.

The identities of the Rpp genes in six accessions with unique or unusual reaction type patterns have also not yet been verified. PI 416778, PI 417126, PI 417129B, PI 506938, PI 567046C, and PI 594796 were only tested in the detached-leaf experiment; thus, we were unable to confirm their unusual reaction patterns using data from the greenhouse assays. Harris et al. (2015) found evidence for more than one Rpp gene in PI 417129B (Kyūshū 40) but the number and identify of the genes have not been confirmed.

The pathogenic variability among the six isolates used in this study reflects some portion of the $P$. pachyrhizi population pathogenic diversity that existed in the field in the years that the isolates were collected. The reactions of the germplasm accessions in the experiments clearly showed that the 2012 isolate from Quincy, FL was the most virulent of the six isolates, followed by the 2011 isolate from the same location. The 2012 isolate also appeared to be more aggressive than the 2011 isolate based on the average numbers of uredinia per lesion that each induced on the PIs that developed the same infection type to both isolates. Both isolates were more virulent than the 2009 isolate from Quincy, which was more similar in virulence to the 2008 and 2009 isolates from Alabama and Louisiana. This pattern is very similar to the pattern of virulence that Walker et al. (2014a) observed in the field in Quincy, FL during the period between 2009 and 2012.

Although pathogenic diversity was lower among the 2008 and 2009 isolates in this study, differences in infection types, particularly in the detached-leaf assays, and in the numbers of uredinia per lesion in both experiments indicated that the four isolates are not pathogenically identical. In the detached-leaf assays, the reactions of PI 417126 to these four isolates suggested that the 2008 and 2009 isolates from Fairhope, AL were similar, and that the 2009 isolates from Louisiana and Florida were similar to one another. In contrast, the reactions of PI 417129B and PI 506938 to the same four isolates suggested similarities between the 2009 isolates from Alabama and Louisiana, and that the 2008 isolate from Alabama and the 2009 isolate from Quincy, FL both had a different pathotype from them. Because the $R p p$ genes have not yet been identified in any of these accessions, they would not have been included in a standard differential set and the pathotype differences that they revealed in this study would have therefore been missed.

If the numbers of uredinia per lesions on the susceptible checks in the two experiments can be considered indications of isolate aggressiveness, the differences observed in the two experiments were either minor or inconsistent (in the case of the Williams 82 reaction to the AL09-FH isolate in the detached-leaf assays). On most of the susceptible control lines, the FL12-Q isolate induced the highest or second highest uredinia per lesion counts, suggesting that it might be somewhat more aggressive than most of the other isolates; however, this still needs to be confirmed with additional investigations.

In summary, this study confirmed moderate to high levels of resistance in at least 45 soybean germplasm accessions to six $P$. pachyrhizi isolates in seedling or detached-leaf assays. Differential reactions were observed in specific PI-isolate combinations that provided information about both the resistance of the plants and the comparative virulence of the isolates. Considerable differences were seen in the reactions of some accessions with a gene at the Rpp1, Rpp3, Rpp4, $R p p 5$, or Rpp6 locus, confirming the likelihood of different alleles at the same $R p p$ locus or undetected resistance genes at other loci. Further molecular and phenotypic investigations will be necessary to resolve which genes are responsible for the resistance of these accessions and PIs with unmapped Rpp genes. The results of these experiments also confirmed that the 2012 isolate from Quincy, FL is unusually virulent against PIs with a variety of Rpp genes, including $R p p 6$, which is historically one of the most effective genes in providing resistance to U.S. populations of $P$. pachyrhizi. The highly resistant soybean PIs in the experiments described here should be of value to soybean breeders. The unusual reaction patterns of several of the accessions indicate that those could be informative if they are included as differentials in future pathotype studies. 


\section{Acknowledgments}

We thank M. K. Pauls (formerly USDA-ARS), J. B. Buckley (Louisiana State University AgCenter, Bossier City, LA), E. Sikora (Auburn University, Auburn, AL), and M. Pegues (Auburn University, Fairhope, AL) for their assistance.

\section{Literature Cited}

Akamatsu, H., Yamanaka, N., Yamaoka, Y., Soares, R. M., Morel, W., Ivanovich, A. J. G., Bogado, A. N., Kato, M., Yorinori, J. T., and Suenaga, K. 2013. Pathogenic diversity of soybean rust in Argentina, Brazil, and Paraguay. J. Gen. Plant Pathol. 79:28-40.

Bernard, R. L., and Cremeens, C. R. 1988. Registration of 'Williams 82' soybean. Crop Sci. 28:1027.

Bonde, M. R., Nester, S. E., Austin, C. N., Stone, C. L., Frederick, R. D., Hartman, G. L., and Miles, M. R. 2006. Evaluation of virulence of Phakopsora pachyrhizi and P. meibomiae isolates. Plant Dis. 90:708-716.

Bromfield, K. R. 1984. Soybean rust. Monograph No. 11. American Phytopathological Society, St. Paul, MN, U.S.A.

Childs, S. P., Buck, J. W., and Li, Z. 2018a. Breeding soybeans with resistance to soybean rust (Phakopsora pachyrhizi). Plant Breed. 137:250-261.

Childs, S. P., King, Z. R., Walker, D. R., Harris, D. K., Pedley, K. F., Buck, J. W., Boerma, H. R., and Li, Z. 2018b. Discovery of a seventh Rpp soybean rust resistance locus in soybean accession PI 605823. Theor. Appl. Genet. 131:27-41.

Diers, B. W., Cary, T. R., Thomas, D. J., and Nickell, C. D. 2006. Registration of 'LD00-3309' soybean. Crop Sci. 46:1384.

Garcia, A., Calvo, E. S., Kiihl, R. A. A., Harada, A., and Hiromoto, D. M. 2008. Molecular mapping of soybean rust (Phakopsora pachyrhizi) resistance genes: Discovery of a novel locus and alleles. Theor. Appl. Genet. 117:545-553.

Godoy, C. V. 2012. Risk and management of fungicide resistance in the Asian soybean rust fungus Phakopsora pachyrhizi. Pages 87-95 in: Fungicide Resistance in Crop Protection: Risk and Management. T. S. Thind, ed. CAB International, Wallingford, U.K.

Harris, D. K., Kendrick, M. D., King, Z. R., Pedley, K. F., Walker, D. R., Cregan, P. B., Buck, J. W., Phillips, D. V., Li, Z., and Boerma, H. R. 2015. Identification of unique genetic sources of soybean rust resistance from the USDA Soybean Germplasm Collection. Crop Sci. 55:2161-2176.

Kendrick, M. D., Harris, D. K., Ha, B., Hyten, D. L., Cregan, P. B., Frederick, R. D., Boerma, H. R., and Pedley, K. F. 2011. Identification of a second Asian soybean rust resistance gene in Hyuuga soybean. Phytopathology 101:535-543.

Konno, S. 1970. Soybean cultivation in Japan. Online at jircas.go.jp/sites/default/ files/publication/jarq/05-2-021-027_0.pdf

Li, S., Smith, J. R., Ray, J. D., and Frederick, R. D. 2012. Identification of a new soybean rust resistance gene in PI 567102B. Theor. Appl. Genet. 125:133-142.

Liu, M., Li, S., Swaminathan, S., Sahu, B. B., Leandro, L. F., Cardinal, A. J., Bhattacharyya, M. K., Song, Q., Walker, D. R., and Cianzio, S. R. 2016. Identification of a soybean rust resistance gene in PI 567104B. Theor. Appl. Genet. 129:863-877.

Miles, M. R., Bonde, M. R., Nester, S. E., Berner, D. K., Frederick, R. D., and Hartman, G. L. 2011. Characterizing resistance to Phakopsora pachyrhizi in soybean. Plant Dis. 95:577-581.

Miles, M. R., Morel, W., Ray, J. D., Smith, J. R., Frederick, R. D., and Hartman, G. L. 2008. Adult plant resistance to Phakopsora pachyrhizi in the field and greenhouse in Paraguay. Plant Dis. 92:96-105.

Monteros, M. J., Missaoui, A. M., Phillips, D. V., Walker, D. R., and Boerma, H. R. 2007. Mapping and confirmation of the 'Hyuuga' red-brown lesion resistance gene for Asian soybean rust. Crop Sci. 47:829-836.

Pantalone, V. R., Allen, F. L., and Landau-Ellis, D. 2003. Registration of '5601T' soybean. Crop Sci. 43:1123.

Paul, C., and Hartman, G. L. 2009. Sources of soybean rust resistance challenged with single-spored isolates of Phakopsora pachyrhizi. Crop Sci. 49:1781-1785.

Paul, C., Hartman, G. L., Marois, J. J., Wright, D. L., and Walker, D. R. 2013. First report of Phakopsora pachyrhizi adapting to soybean genotypes with the Rppl or Rpp6 rust resistance genes in field plots in the United States. Plant Dis. 97: 1379.

Paul, C., Hill, C. B., and Hartman, G. L. 2011. Comparisons of visual rust assessments and DNA levels of Phakopsora pachyrhizi in soybean genotypes varying in rust resistance. Plant Dis. 95:1007-1012.

Ray, J. D., Morel, W., Smith, J. R., Frederick, R. D., and Miles, M. R. 2009. Genetics and mapping of adult plant rust resistance in soybean PI 587886 and PI 587880A. Theor. Appl. Genet. 119:271-280.

Ribeiro, A. S., Moreira, J. U. V., Pierozzi, P. H. B., Rachid, B. F., Toledo, J. F. F., Arias, C. A. A., Soares, R. M., and Godoy, C. V. 2007. Genetic control of Asian rust in soybean. Euphytica 157:15-25.

Schmitz, H. K., Madeiros, C.-A., Craig, I. R., and Stammler, G. 2014. Sensitivity of Phakopsora pachyrhizi towards quinone-outside-inhibitors and demethylationinhibitors, and corresponding resistance mechanisms. Pest Manage. Sci. 70: 378-388.

Schneider, R. W., Hollier, C. A., Whitam, H. K., Palm, M. E., McKemy, J. M., Hernandez, J. R., Levy, L., and DeVries-Paterson, R. 2005. First report of soybean rust caused by Phakopsora pachyrhizi in the continental United States. Plant Dis. 89:774.

Shaner, G., Stromber, E. L., Lacy, G. H., Barker, K. R., and Pirone, T. P. 1992. Nomenclature and concepts of pathogenicity and virulence. Annu. Rev. Phytopathol. 30:47-66.

Song, Q. J., Hyten, D. L., Jia, G., Quigley, C. V., Fickus, E. W., Nelson, R. L., and Cregan, P. B. 2015. Fingerprinting soybean germplasm and its utility in genomic research. G3 (Bethesda) 5:1999-2006.

Twizeyimana, M., and Hartman, G. L. 2012. Pathogenic variation of Phakopsora pachyrhizi isolates on soybean in the United States from 2006 to 2009. Plant Dis. 96:75-81.

Twizeyimana, M., Ojiambo, P. S., Haudenshield, J. S., Caetano-Anollés, G., Pedley, K. F., Banyopadhyay, R., and Hartman, G. L. 2011. Genetic structure and diversity of Phakopsora pachyrhizi isolates from soyabean. Plant Pathol. 60:719-729.

Vuong, T. D., Walker, D. R., Nguyen, B. T., Nguyen, T. T., Dinh, H. X., Hyten, D. L., and Nguyen, T. 2016. Molecular characterization of resistance to soybean rust (Phakopsora pachyrhizi Syd. \& Syd.) in soybean cultivar DT PI 635999. PLoS One 11:e0164493.

Walker, D. R., Boerma, H. R., Phillips, D. V., Schneider, R. W., Buckely, J. B., Shipe, E. R., Mueller, J. D., Weaver, D. B., Sikora, E. J., Moore, S. H., Hartman, G. L., Miles, M. R., Harris, D. K., Wright, D. L., Marois, J. J., and Nelson, R. L. 2011. Evaluation of USDA soybean germplasm accessions for resistance to soybean rust in the southern United States. Crop Sci. 51:678-693.

Walker, D. R., Harris, D. K., King, Z. R., Li, Z., Boerma, H. R., Buckley, J. B., Weaver, D. B., Sikora, E. J., Shipe, E. R., Wright, D. L., and Nelson, R. L. 2014a. Evaluation of soybean germplasm accessions for resistance to Phakopsora pachyrhizi populations in the southeastern United States, 20092012. Crop Sci. 54:1673-1689.

Walker, D. R., Harris, D. K., King, Z. R., Li, Z., Phillips, D. V., Buck, J. W., Nelson, R. L., and Boerma, H. R. 2014b. Reactions of soybean germplasm accessions to soybean rust isolates from Georgia. Crop Sci. 54:1433-1447.

Yamanaka, N., Lemos, N. G., Uno, M., Akamatsu, H., Yamaoka, Y., Abdelnoor, R. V., Bracchini, A. L., and Suenaga, K. 2013. Resistance to Asian soybean rust in soybean lines with the pyramided three Rpp genes. Crop Breed. Appl. Biotechnol. 13:75-82.

Yamanaka, N., Yamaoka, Y., Kato, M., Lemos, N. G., Passionotto, A. L. L., dos Santos, J. V. M., Benitez, E. R., Abdelnoor, R. V., Soares, R. M., and Suenaga, K. 2010. Development of classification criteria for resistance to soybean rust and differences in virulence among Japanese and Brazilian rust populations. Trop. Plant Pathol. 35:153-162.

Yorinori, J. T., Paiva, W. M., Frederick, R. D., Costamilan, L. M., Bertagnolli, P. F., Hartman, G. L., Godoy, C. V., and Nunes, J., Jr. 2005. Epidemics of soybean rust (Phakopsora pachyrhizi) in Brazil and Paraguay from 2001 to 2003. Plant Dis. 89:675-677. 